\title{
Synthesis, spectral and structural properties of bis-imidazoline selones
}

\author{
ARRURI SATHYANARAYANA, KATAM SRINIVAS, ANINDITA MANDAL, \\ SASWATI GHARAMI and GANESAN PRABUSANKAR* \\ Department of Chemistry, Indian Institute of Technology Hyderabad, ODF Estate, \\ Yeddumailaram, 502205 India \\ e-mail: prabu@iith.ac.in
}

MS received 29 March 2014; revised 10 May 2014; accepted 14 May 2014

\begin{abstract}
New biphenyl derivatives of bis-imidazoline selones were synthesized in good yield and characterized by multinuclear (1D and 2D) NMR and UV-vis studies. The solid state structures of bis-imidazoline selones were further confirmed by single crystal $\mathrm{X}$ ray diffraction technique.
\end{abstract}

Keywords. Imidazole; selenium; selone; biphenyl.

\section{Introduction}

Organo selenium derivatives have been now established as essential trace element for thyroid functions. ${ }^{1}$ The selenium analogue can show antioxidant activity by reducing $\mathrm{H}_{2} \mathrm{O}_{2}$ even in presence of Glutathione (GSH). ${ }^{1-6}$ Guziec et al. was the first to synthesize imidazole based thione ligand (MMI) and its selenium analogues. ${ }^{7}$ These types of selenium compounds can be biologically significant when coordinated with biologically important transition metals $(\mathrm{Cu}, \mathrm{Fe}, \mathrm{Ni}, \mathrm{Zn}, \mathrm{Mn}$, Mo, etc.). ${ }^{8-10}$ Several such examples of bis-imidazoline selone compounds were synthesized for different applications. For instance, group- 9 complexes of coordination 1,1'-methylenebis(3-methylimidazoline-2selone) [Mbis], 1,1'-(1,2-ethanediyl)bis(3-methylimidazoline-2-selone) [Ebis], 1,1-(butane-1,4-diyl)bis(3methylimidazoline-2-selone) [Bbis] and 1,1'-(pentane1,5-diyl)bis(3-methylimid-azoline-2-selone) [Pbis] ligands were reported by Lippolis et al. ${ }^{11}$ and Mugesh et al. ${ }^{1}$ in 2011 (chart 1). Later in 2008, Mbis and Ebis ligands were synthesized by Jin et al. and introduced to cyclopentadienyl group $\left(\mathrm{Cp}^{*}\right)$ which resulted in the first half-sandwich iridium and rhodium complexes. ${ }^{12}$ Recently, a method for synthesis of 1,1'-methylene-bis(3-aryl-imidazole-2-ylidene) ligands and derivatisation with chalcogenides was reported by Danopoulos et al. in 2013 (chart 1). ${ }^{13}$ The known bis imidazoline selones were isolated with alkyl bridging groups, where the two biologically active selones are expected to function

*For correspondence

This paper is dedicated to Professor S S Krishnamurthy. at the same site. On the other hand, separation of selone active centres by long range rigid spacers can provide enough room to show the independent activities. Similar such examples are not synthesized yet. Thus, we report the first aryl bridged bis-imidazoline selones from a straight forward route. The imidazoselone compounds were prepared by treating imidazolium salt having biphenyl spacer with selenium powder in the presence of potassium carbonate.

\section{Experimental}

\subsection{General remarks}

All manipulations were carried out under argon using Schlenk line techniques. The solvents were purchased from commercial sources and purified according to standard procedures. ${ }^{14}$ Methyl imidazole, allyl imidazole, acetonitrile, methanol, potassium carbonate, selenium powder and 4,4'-bis(chloromethyl)-1,1' -biphenyl (1) were purchased from commercial sources. FT-IR measurements were carried out on a Bruker Alpha-P Fourier transform spectrometer. The UV- vis spectra were measured on a T90+ UV-visible spectrophotometer. NMR spectra were recorded on Bruker Ultrashield 400 spectrometer at $25^{\circ} \mathrm{C}$, unless otherwise stated. Chemical shifts are given relative to $\mathrm{Me}_{4} \mathrm{Si}$ and were referenced to the solvent resonances as internal standards. The crystal structure of $\mathbf{3 a}$ and $\mathbf{3 b}$ were measured on an Oxford Supernova diffractometer. Single crystals were mounted on a Goniometer KM4/Xcalibur equipped with Sapphire2 (large Be window) detector $\left(\mathrm{CuK}_{\alpha}\right.$ radiation source, $\lambda=1.5418 \AA$ ). Crystals of 3a and $\mathbf{3 b}$ were obtained from mixture of dichloromethane 


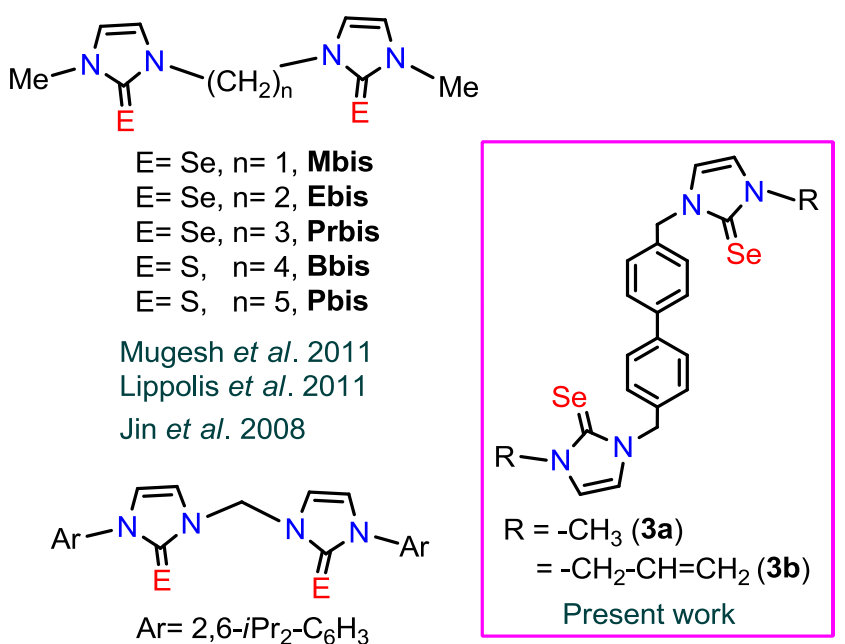

$\mathrm{E}=\mathrm{Se}, \mathrm{L}^{\mathrm{DiPP}} \mathrm{Se}_{2}$

Danopoulos et al. 2013

Chart 1. Known bis-imidazoline selones.

and ethanol solution of $\mathbf{3 a}$ and $\mathbf{3 b}$ at room temperature over a period of 12 hours. Data were collected at 150 $\mathrm{K}$. Using Olex2, the structure was solved with the olex2.solve structure solution program using Charge Flipping and refined with the olex2.refine refinement package using Gauss-Newton minimisation. ${ }^{15}$

\subsection{Synthesis of $2 a$}

Acetonitrile ( $35 \mathrm{~mL}$ ) was added to $\mathbf{1}(5 \mathrm{~g}, 19.9 \mathrm{mmol})$ under argon atmosphere then $\mathrm{N}$-methyl imidazole $\left(4.7 \mathrm{~mL}, 59.7 \mathrm{mmol}\right.$ ) was added to it at $90^{\circ} \mathrm{C}$ temperature and stirred for $46 \mathrm{~h}$. The reaction progress was monitored by TLC. After completion of the reaction, the product, 2a was formed as white precipitate. Yield: $98 \%$ (based on 1). M.p. $102-104^{\circ} \mathrm{C}$ (melted to transparent liquid). ${ }^{1} \mathrm{H}$ NMR $\left(\mathrm{D}_{2} \mathrm{O}, 400 \mathrm{MHz}\right): \delta 8.75(\mathrm{~s}$, $1 \mathrm{H}, \operatorname{Im} H), 7.67-7.65\left(\mathrm{~d},{ }^{2} J_{H H}=6.8 \mathrm{~Hz}, 4 \mathrm{H}, \operatorname{Im} H\right)$, 7.46-7.44(d, $\left.{ }^{2} J_{H H}=8 \mathrm{~Hz}, 4 \mathrm{H}, \operatorname{Ar} H\right), 7.41-7.40(\mathrm{~d}$, $\left.{ }^{2} J_{H H}=4 \mathrm{~Hz}, 6.6 \mathrm{~Hz}, 4 \mathrm{H}, \operatorname{ArH}\right), 5.37\left(\mathrm{~s}, 4 \mathrm{H}, \mathrm{NCH}_{2}\right)$, 3.84 (s, 6H, $\left.\mathrm{CH}_{3}\right)$ ppm. ${ }^{13} \mathrm{C}$ NMR $\left(\mathrm{D}_{2} \mathrm{O}, 100 \mathrm{MHz}\right): \delta$ 122.09, $123.83(\mathrm{Im}-\mathrm{CH}), 133.23,140.27$ (Ph-C), 35.72 $\left(\mathrm{CH}_{3}\right), 129.21,127.61(\mathrm{Ph}-\mathrm{C}), 52.34\left(\mathrm{~N}-\mathrm{CH}_{2}-\right) \mathrm{ppm}$. FT-IR (neat, $v$ ): 3367(s), 3296(m), 3138(m), 3118(m), 3077(m), 2984(m), 2845(w), 1652(w), 1569(s), 1560(s), 1501(m), 1453(m), 1186(m), 1159(s), 801(m), $753(\mathrm{~s}) \mathrm{cm}^{-1}$.

\subsection{Synthesis of $\mathbf{2 b}$}

Acetonitrile $(25 \mathrm{~mL})$ was added to $\mathbf{1}(5 \mathrm{~g}, 19.9$ mmol) under argon atmosphere with stirring. Then allyl imidazole $(6.43 \mathrm{~mL}, 59.6 \mathrm{mmol})$ was added to the reaction mixture and stirred for $16 \mathrm{~h}$ at $90^{\circ} \mathrm{C}$. The reaction progress was monitored by TLC. The volatiles were removed under reduced pressure, then the crude product was washed with diethyl ether $(5 \mathrm{~mL} \times 3)$ and dried under high vacuum to obtain off-white solid, 2b. Yield: $95 \%$ (based on 1). M.p. $74-76^{\circ} \mathrm{C}$ (melted to transparent liquid). ${ }^{1} \mathrm{H}$ NMR $\left(\mathrm{D}_{2} \mathrm{O}, 400 \mathrm{MHz}\right): \delta$ 7.50 (s, 4H, $\operatorname{Im} H), 7.42-7.40$ (m, 8H, ArH), 5.93-5.87 $\left(\mathrm{m}, 2 \mathrm{H}, \mathrm{CH}_{2}=\mathrm{CH}-\right), 5.37-5.34\left(\mathrm{~m}, 6 \mathrm{H}, \mathrm{CH}_{2}=\mathrm{CH}-\right.$, merged with $\left.\mathrm{NCH}_{2}\right), 5.30-5.26\left(\mathrm{~d},{ }^{2} J_{H H}=16 \mathrm{~Hz}, 2 \mathrm{H}\right.$, $\left.\mathrm{CH}_{2}=\mathrm{CH}-\right), 4.70\left(\mathrm{~s}, 4 \mathrm{H}, \mathrm{NCH}_{2}\right)$ ppm. The imidazolium proton $(\mathrm{N}-\mathrm{CH}-\mathrm{N})$ peak is not obtained as it has been exchanged with $\mathrm{D}_{2} \mathrm{O} .{ }^{13} \mathrm{C}$ NMR $\left(\mathrm{D}_{2} \mathrm{O}, 100\right.$ $\mathrm{MHz}): \delta$ 122.74, $122.33(\mathrm{Im}-\mathrm{CH}), 130.18,140.31$ $(\mathrm{Ph}-\mathrm{C}) 121.23\left(\mathrm{CH}_{2}=\mathrm{CH}\right), 133.23\left(\mathrm{CH}_{2}=\mathrm{CH}-\right), 51.61$ $\left(\mathrm{CH}_{2}=\mathrm{CH}-\mathrm{CH}_{2}-\right), 129.23,127.66(\mathrm{Ph}-\mathrm{C}), 52.48(\mathrm{~N}-$ $\mathrm{CH}_{2^{-}}$) ppm. FT-IR (neat, $v$ ): 3358(s), 3242(w), 3121(m), 3058(m), 2845(w), 1643(w), 1621(w), 1555(s), 1397(m), 1207(w), 1192(w), 1141(s), 995(m), 961(s), 849(s), 804(s), 754(s) $\mathrm{cm}^{-1}$.

\subsection{Synthesis of $3 a$}

In a schlenk tube, $\mathbf{2 a}(4 \mathrm{~g}, 9.63 \mathrm{mmol})$ was added to activated potassium carbonate $(2.6 \mathrm{~g}, 19.26 \mathrm{mmol})$. To which, $\mathrm{MeOH}(10 \mathrm{~mL})$ was added then Se powder $(1.5 \mathrm{~g}, 19.26 \mathrm{mmol})$ was added under argon atmosphere. The temperature was set at $70^{\circ} \mathrm{C}$ and the reaction mixture was stirred for $24 \mathrm{~h}$. The progress of the reaction was monitored by TLC. After completion of reaction, the reaction mixture was transferred to a flask and the solvent was evaporated. Then water was added to it and extracted with dichloromethane $(3 \times$ $15 \mathrm{~mL}$ ). The organic extract was washed with brine solution, dried over anhydrous $\mathrm{Na}_{2} \mathrm{SO}_{4}$. Organic solvent was evaporated under reduced pressure to result crude amorphous off-white product, 3a. Yield: 55\% (based on 2a). M.p., $168-170^{\circ} \mathrm{C}$ (became brown), $260-262^{\circ} \mathrm{C}{ }^{1} \mathrm{H}$ NMR $\left(\mathrm{CDCl}_{3}, 400 \mathrm{MHz}\right): \delta 7.54$ $7.52\left(\mathrm{~d},{ }^{2} J_{H H}=8 \mathrm{~Hz}, 4 \mathrm{H}, \operatorname{Ar} H\right), 7.40-7.38(\mathrm{~d}$, $\left.{ }^{2} J_{H H}=4 \mathrm{~Hz}, 4 \mathrm{H}, \mathrm{Ar} H\right), 6.86-6.85\left(\mathrm{~d},{ }^{2} J_{H H}=4\right.$ $\mathrm{Hz}, 2 \mathrm{H}, \operatorname{Im} H), 6.78-6.77\left(\mathrm{~d},{ }^{2} J_{H H}=4 \mathrm{~Hz}, 2 \mathrm{H}\right.$, $\mathrm{Im} H), 5.38\left(\mathrm{~s}, 4 \mathrm{H}, \mathrm{CH}_{2}\right) 3.75\left(\mathrm{~s}, 6 \mathrm{H}, \mathrm{CH}_{3}\right) \mathrm{ppm} .{ }^{13} \mathrm{C}$ NMR $\left(\mathrm{CDCl}_{3}, 100 \mathrm{MHz}\right): \delta 155.40(C=\mathrm{Se}), 139.06$ $(\mathrm{Ph}-\mathrm{C}), 135.95\left(\mathrm{CH}_{2}-\mathrm{C}\right), 128.31(\mathrm{Im}-\mathrm{CH}), 126.68$ $(\mathrm{Ph}-\mathrm{CH}), 120.95(\mathrm{Im}-\mathrm{CH}), 119.29(\mathrm{Im}-\mathrm{CH}), 51.1(\mathrm{~N}-$ $\left.\mathrm{CH}_{2}\right), 36.53\left(\mathrm{~N}-\mathrm{CH}_{3}\right)$ ppm. FT-IR (neat, v): $3130(\mathrm{w})$, 2958(w), 2921(m), 2851(m), 2349(w), 2149(w), 1665(m), 1564(w), 1496(w), 1459(s), 1392(s), 1360(s), 1260(m), 1228(s), 1186(m), 1116(m), 1083(m), 1018(m), 940(w), 845(m), 801(s), 760(s), 706(s), $669(\mathrm{~s}) \mathrm{cm}^{-1}$. 


\subsection{Synthesis of $\mathbf{3 b}$}

Potassium carbonate $(2.1 \mathrm{~g}, 8.03 \mathrm{mmol})$ was heated for about $10 \mathrm{~min}$. by hot airgun and after cooling it for sometimes, $\mathbf{2 b}(2 \mathrm{~g}, 4.02 \mathrm{mmol})$ and Se powder (0.634 g, $8.04 \mathrm{mmol})$ were added under argon atmosphere and then methanol $(25 \mathrm{~mL})$ was added to the reaction mixture. Then the reaction mixture was stirred for $36 \mathrm{~h}$ at $70^{\circ} \mathrm{C}$. The progress of the reaction was monitored by TLC. After completion of the reaction, water was added to the reaction mixture and extracted with dichloromethane $(3 \times 15 \mathrm{~mL})$. The organic extract was washed with brine solution, dried over anhydrous $\mathrm{Na}_{2} \mathrm{SO}_{4}$. Organic solvent was evaporated under reduced pressure. As a result crude amorphous yellowish product was obtained. Yield: $70 \%$ (based on 2b). M.p. $214-218^{\circ} \mathrm{C}$ (melted to black). ${ }^{1} \mathrm{H}$ NMR $\left(\mathrm{CDCl}_{3}, 400 \mathrm{MHz}\right): \delta 7.53-7.51\left(\mathrm{~d},{ }^{2} J_{H H}=8 \mathrm{~Hz}\right.$, $4 \mathrm{H}, \operatorname{Ar} H), 7.39-7.37\left(\mathrm{~d},{ }^{2} J_{H H}=8 \mathrm{~Hz}, 4 \mathrm{H}, \operatorname{Ar} H\right)$, 6.85-6.84 (d, $\left.{ }^{2} J_{H H}=4 \mathrm{~Hz}, 2 \mathrm{H}, \operatorname{Im} H\right), 6.79-6.78(\mathrm{~d}$, $\left.{ }^{2} J_{H H}=4 \mathrm{~Hz}, 2 \mathrm{H}, \mathrm{Im} H\right), 6.0-5.90\left(\mathrm{~m}, 2 \mathrm{H}, \mathrm{CH}_{2}=\mathrm{CH}-\right)$, $5.40\left(\mathrm{~s}, 4 \mathrm{H}, \mathrm{Ar}-\mathrm{CH}_{2}-\mathrm{Im}\right), 5.32-5.29\left(\mathrm{~d},{ }^{2} J_{H H}=12 \mathrm{~Hz}\right.$, $\left.2 \mathrm{H}, \mathrm{CH}_{2}=\mathrm{CH}-\right), 5.28-5.23\left(\mathrm{~d},{ }^{2} J_{H H}=16 \mathrm{~Hz}, 2 \mathrm{H}\right.$, $\left.\mathrm{CH}_{2}=\mathrm{CH}-\right), 4.82-4.80\left(\mathrm{~d},{ }^{2} \mathrm{~J}_{H H}=4 \mathrm{~Hz}, 4 \mathrm{H}, \mathrm{Im}-\mathrm{CH}_{2}-\right.$ $\mathrm{CH}=)$ ppm. ${ }^{13} \mathrm{C} \mathrm{NMR}\left(\mathrm{CDCl}_{3}, 100 \mathrm{MHz}\right): \delta 156.64$ $(C=\mathrm{Se}), 140.38(\mathrm{Ph}-C), 134.70\left(\mathrm{CH}_{2}-C\right), 139.59$ (Im$C \mathrm{H}), 128.77(\mathrm{Ph}-\mathrm{CH}), 127.46\left(\mathrm{CH}_{2}-\mathrm{Ph}-\mathrm{C}\right), 119.57$ $\left(\mathrm{CH}_{2}=\mathrm{CH}\right), 118.73\left(\mathrm{CH}_{2}=\mathrm{CH}\right), 118.62(\mathrm{Im}-\mathrm{CH}), 52.75$ $\left(=\mathrm{CH}-\mathrm{CH}_{2}\right), 52.24(\mathrm{~N}-\mathrm{CH})$ ppm. FT-IR (neat, $\left.v\right)$ : 2922(w), 2850(w), 2342(w), 2148(w), 1665(m), $1566(\mathrm{~m}), \quad 1496(\mathrm{~m}), \quad 1447(\mathrm{~m}), \quad 1397(\mathrm{~s}), \quad 1220(\mathrm{~m})$, 1170(m), 1103(w), 1044(w), 990(m), 935(m), 730(s), $619(\mathrm{~m}) \mathrm{cm}^{-1}$.

\section{Results and Discussion}

\subsection{Synthesis and characterization of $2 \boldsymbol{a}$ and $\mathbf{2 b}$}

As outlined in scheme 1, compounds $\mathbf{2 a}$ and $\mathbf{2 b}$ were obtained in excellent yield by combining $\mathrm{N}$-methyl or allyl imidazole with 4,4'-bis(chloromethyl)-1,1'biphenyl (1) in acetonitrile at $90^{\circ} \mathrm{C}$ under argon atmosphere. Compounds $\mathbf{2 a}$ and $\mathbf{2 b}$ were soluble in water and hygroscopic in nature. $\mathbf{2} \mathbf{a}$ and $\mathbf{2} \mathbf{b}$ were characterized by FT-IR, UV-vis, ${ }^{1} \mathrm{H}$ NMR and ${ }^{13} \mathrm{C}$ NMR techniques. In 2a, the $\mathrm{N}_{2} \mathrm{CH}$ peak appeared at $\delta 8.75$ ppm, while it is absent for $\mathbf{2} \mathbf{b}$ due to fast proton exchange of $\mathrm{N}_{2} \mathrm{CH}$ by deuterium. The $\mathrm{N}-\mathrm{CH}_{2}$ peak appeared at $\delta 5.37 \mathrm{ppm}$ for $\mathbf{3 a}$, while it is upfield shifted $(\delta 4.70 \mathrm{ppm})$ for $\mathbf{3 b}$.

\subsection{Synthesis and characterization of $\mathbf{3 a}$ and $\mathbf{3 b}$}

In a schlenk tube $\mathbf{2 a}$ or $\mathbf{2 b}$ were further heated with 2 equivalent of activated potassium carbonate and 2 equivalent of Se powder in methanol at $70^{\circ} \mathrm{C}$ to result 3a and $\mathbf{3 b}$, respectively (scheme 1 ). Compound $\mathbf{3 a}$ is soluble in methanol-dichloromethane mixture, while $\mathbf{3 b}$ is soluble only in dichloromethane. 3a is off-white solid whereas the colour of $\mathbf{3 b}$ is yellowish. The compounds $\mathbf{3 a}$ and $\mathbf{3 b}$ were characterized by FT-IR, ${ }^{1} \mathrm{H}$ NMR, ${ }^{13} \mathrm{C}$ NMR, UV-vis and single crystal X-ray diffraction techniques. The selected characterization parameters for $\mathbf{2 a}$, $\mathbf{2 b}, \mathbf{3} \mathbf{a}$ and $\mathbf{3 b}$ are listed in table 1 . In $\mathbf{3 a}, \mathbf{C}=$ Se streching frequency appeared at $1116 \mathrm{~cm}^{-1}$ while in $\mathbf{3 b}$ it appeared at $1103 \mathrm{~cm}^{-1} .^{12}$ The N-C-N stretching frequency for $\mathbf{3 a}$ and $\mathbf{3 b}$ are comparable. ${ }^{12}$ In ${ }^{1} \mathrm{H}$ NMR, the chemical shift values for Im- $\mathrm{CH}, \mathrm{Im}-\mathrm{CH}_{2}$ and aryl protons are comparable in $\mathbf{3 a}$ and $\mathbf{3 b}$. In ${ }^{13} \mathrm{C}$ NMR, the $C=$ Se chemical shift value for $\mathbf{3} \mathbf{a}$ and $\mathbf{3 b}$ are comparable ( $\delta 155.4 \mathrm{ppm}$ for $\mathbf{3 a}$ and $\delta 156.6 \mathrm{ppm}$ for $\mathbf{3 b}$ ). Similarly, the ${ }^{13} \mathrm{C}$ NMR chemical shift values of $\mathrm{Im}-\mathrm{CH}_{2}$ for 3a $(\delta 51.1 \mathrm{ppm})$ and $\mathbf{3 b}(\delta 52.75 \mathrm{ppm})$ are comparable.

The formation of $\mathbf{3 a}$ and $\mathbf{3 b}$ were further characterized by 2D NMR spectroscopy (DEPT, HMBC and HSQC). Notably the structural exploration for the imidazole selone using 2D NMR is rare. The structures of 3a and 3b are confirmed by 2D NMR studies, which are further verified by single crystal X-ray diffraction study (vide infra). Therefore the present investigation

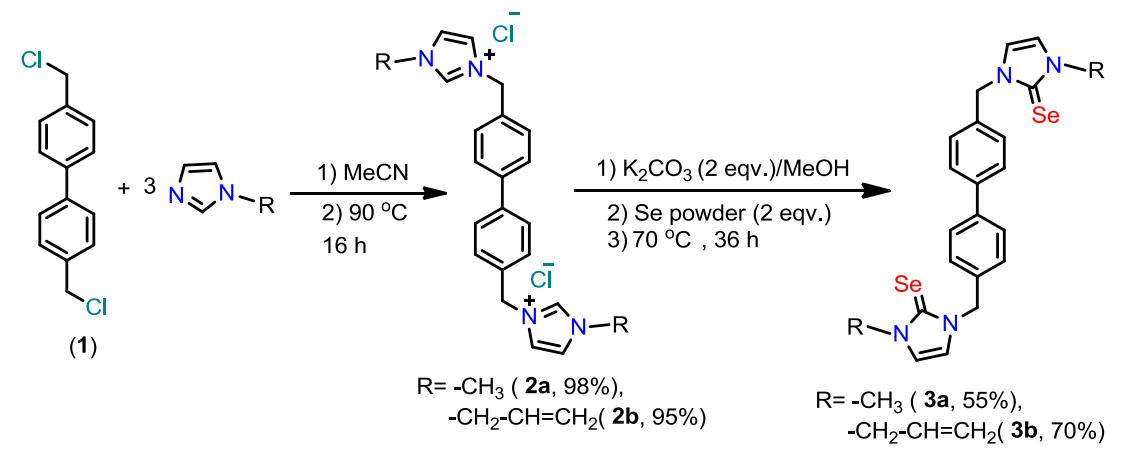

Scheme 1. Synthesis of $\mathbf{2 a}, \mathbf{2 b}, \mathbf{3 a}$ and $\mathbf{3 b}$. 
Table 1. Analytical and spectral data of $\mathbf{2 a}, \mathbf{2 b}, \mathbf{3 a}$ and $\mathbf{3 b}$.

\begin{tabular}{|c|c|c|c|c|c|c|}
\hline Compound & M.p. $\left({ }^{\circ} \mathrm{C}\right)$ & Yield (\%) & $\begin{array}{c}{ }^{1} \mathrm{H} \text { NMR } \delta \\
\text { Im-CH (ppm) }\end{array}$ & $\begin{array}{c}{ }^{13} \mathrm{C} \text { NMR } \delta \\
\mathrm{N}-C-\mathrm{N}(\mathrm{ppm})\end{array}$ & $\begin{array}{c}\text { Solution } \\
\text { UV-vis abs. }(\mathrm{nm})\end{array}$ & $\begin{array}{c}\text { Solid state } \\
\text { UV-vis abs. }(\mathrm{nm})\end{array}$ \\
\hline $2 \mathbf{a}$ & $102-104$ & 98 & 7.67 & & 263 & 286 \\
\hline $2 b$ & $74-76$ & 95 & 7.5 & & 262 & 267 \\
\hline $3 \mathbf{a}$ & $260-262$ & 55 & $\begin{array}{l}6.86-6.85 \\
6.78-6.77\end{array}$ & 155.40 & 272 & 341 \\
\hline $3 b$ & 214-218 & 70 & $\begin{array}{l}6.85-6.84 \\
6.79-6.78\end{array}$ & 156.64 & 273 & 322 \\
\hline
\end{tabular}

can help to assign the unknown structures of similar class of compounds in biological system. In DEPT spectrum, 3a showed the existence of one $\mathrm{CH}_{2}$ group, one $\mathrm{CH}_{3}$ group and four $\mathrm{CH}$ groups, while $\mathbf{3 b}$ displayed three $\mathrm{CH}_{2}$ groups and five $\mathrm{CH}$ groups which are in accordance with the structures of $\mathbf{3 a}$ and $\mathbf{3 b}$ (vide infra).

HSQC spectrum of $\mathbf{3 a}$ and $\mathbf{3 b}$ both showed $\mathrm{CH}$ correlations as follows, the imidazolium $\mathrm{CH}$ group showed strong correlation between the carbons and hydrogen attached to corresponding moieties. The $\mathrm{CH}$ group of benzene ring also showed a strong correlation between $\mathrm{CH}$ carbon and hydrogen atom attached and in $\mathrm{CH}_{2}$ group, the $\mathrm{CH}$ correlation is also observed. In $\mathbf{3 a}$, the $\mathrm{CH}$ correlation of $\mathrm{CH}_{3}$ group is observed whereas in $\mathbf{3 b}$, the $\mathrm{CH}$ correlation of allyl group is also observed. From this, the complete $\mathrm{CH}$ correlations are confirmed.

The structures of $\mathbf{3 a}$ and $\mathbf{3 b}$ are further confirmed by HMBC spectrum that showed the mapping of carbon coupling with neighbouring protons. In $\mathbf{3 a}$, the $\mathrm{CH}_{2}$ proton couples strongly with the nearest imidazolium carbons $\left({ }^{3} \mathrm{~J}\right)$, it also couples with the nearest carbon atom $\left({ }^{3} \mathrm{~J}\right)$ of $\mathrm{CH}$ group in benzene ring but does not couple with the farthest one. Coupling between the mentioned $\mathrm{CH}_{2}$ carbon and the quaternary carbon of benzene ring is quite strong $\left({ }^{2} \mathrm{~J}\right)$. The proton of $\mathrm{CH}_{3}$ group strongly couples with the nearest Imidazolium carbons $\left({ }^{3} \mathrm{~J}\right)$. The $\mathrm{CH}_{3}$ carbon couples with the nearest Imidazolium proton $\left({ }^{3} \mathrm{~J}\right)$. Another strong correlation is observed between $\mathrm{CH}_{2}$ carbon and nearest aromatic proton $\left({ }^{3} \mathbf{J}\right)$. Whereas in $\mathbf{3 b}$, the $\mathrm{CH}_{2}$ carbon couples with the nearest proton of the benzene ring $\left({ }^{3} \mathrm{~J}\right) . \mathrm{CH}_{2}$ carbon of the allyl group attached to nitrogen atom couples with the $\mathrm{CH}$-proton $\left({ }^{2} \mathrm{~J}\right)$ of allyl moiety and $\mathrm{CH}_{2}$-proton $\left({ }^{3} \mathrm{~J}\right)$ of allyl moiety. $\mathrm{CH}$ carbon of allyl moiety shows correlation with the imidazole proton $\left({ }^{4} \mathrm{~J},{ }^{3} \mathrm{~J}\right) \cdot \mathrm{CH}_{2}$ proton of allyl moiety attached to nitrogen shows correlation with nearest $\mathrm{CH}$ carbon $\left({ }^{3} \mathrm{~J}\right)$ of imidazolium moiety. Protons of the $\mathrm{CH}_{2}$ group, nearest to the benzene ring show correlation to the neighbouring carbon atom $\left({ }^{4} \mathrm{~J}\right)$ of that benzene ring. Imidazolium $\mathrm{CH}$-carbon couples with the $\mathrm{CH}_{2}-$ proton $\left({ }^{4} \mathrm{~J}\right)$ of the allyl moiety. Quaternary carbon of benzene ring shows correlation with the neighbouring $\mathrm{CH}_{2}$ proton $\left({ }^{2} \mathrm{~J}\right)$. The carbon containing selenium correlates with the imidazolium protons $\left({ }^{3} \mathrm{~J},{ }^{3} \mathrm{~J}\right)$ and it also correlates with protons of both the neighbouring $\mathrm{CH}_{2}$ moieties $\left({ }^{3} \mathrm{~J},{ }^{3} \mathrm{~J}\right)$.

\subsection{UV-vis solid and solution state absorption spectra of $2 a, 2 b, 3 a$ and $3 b$}

Solution state UV-vis absorption spectrum of $\mathbf{2 a}, \mathbf{2} \mathbf{b}$, $\mathbf{3 a}$ and $\mathbf{3 b}$ were measured in DMSO (figure 1). The solution state UV-vis absorption patterns of $\mathbf{2 a}, \mathbf{2} \mathbf{b}$, $\mathbf{3 a}$ and $\mathbf{3 b}$ are comparable. The absorption properties of $\mathbf{2 a}$ and $\mathbf{2 b}$ are much stronger than $\mathbf{3 a}$ and $\mathbf{3 b}$. $\mathbf{2 a}$ and $2 \mathbf{b}$ both shows an absorption band at 262 and 263 nm due to $\pi-\pi^{*}$ transition, in which absorption of $\mathbf{2 b}$ $\left(\epsilon=84623 \mathrm{~L} \mathrm{~mol}^{-1} \mathrm{~cm}^{-1}\right)$ is stronger than $2 \mathbf{a}(\epsilon=$ $\left.65427 \mathrm{~L} \mathrm{~mol}^{-1} \mathrm{~cm}^{-1}\right)$. Similarly, 3a shows an absorption band at $270 \mathrm{~nm}$ with higher molar extinction coefficient $\left(\epsilon=50552 \mathrm{~L} \mathrm{~mol}^{-1} \mathrm{~cm}^{-1}\right)$ compared to $\mathbf{3 b}(274$ $\mathrm{nm}, \epsilon=43015 \mathrm{~L} \mathrm{~mol}^{-1} \mathrm{~cm}^{-1}$ ) due to $\pi-\pi *$ transition. The solid state UV-vis absorption spectra of $\mathbf{2 a}, \mathbf{2} \mathbf{b}$, $\mathbf{3 a}$ and $\mathbf{3 b}$ are different from respective solution state spectra (figure 2).

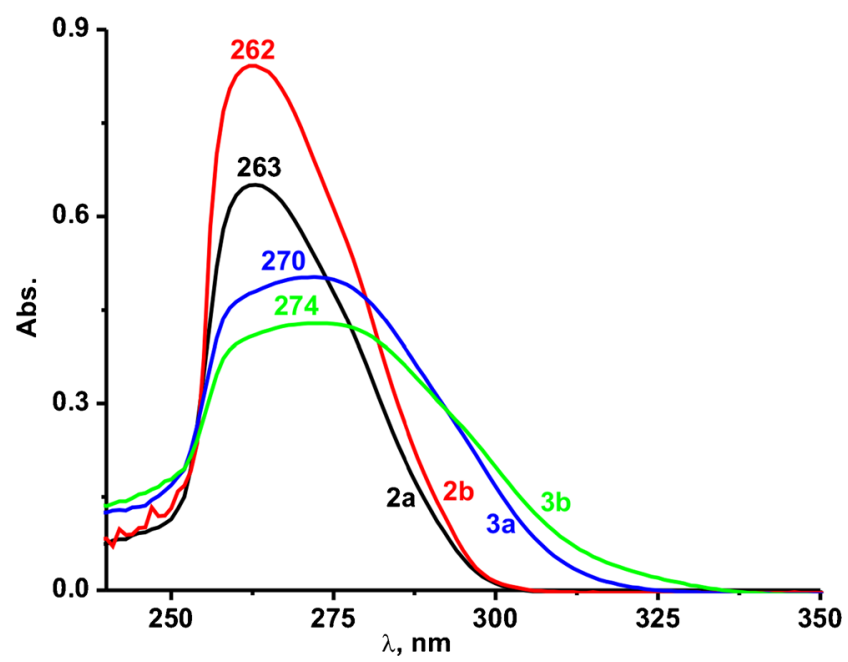

Figure 1. The solution state UV-vis spectra of $\mathbf{2 a}, \mathbf{2 b}, \mathbf{3 a}$ and $\mathbf{3 b}$ in DMSO at RT $\left(9.95 \times 10^{-6} \mathrm{M}\right)$. 


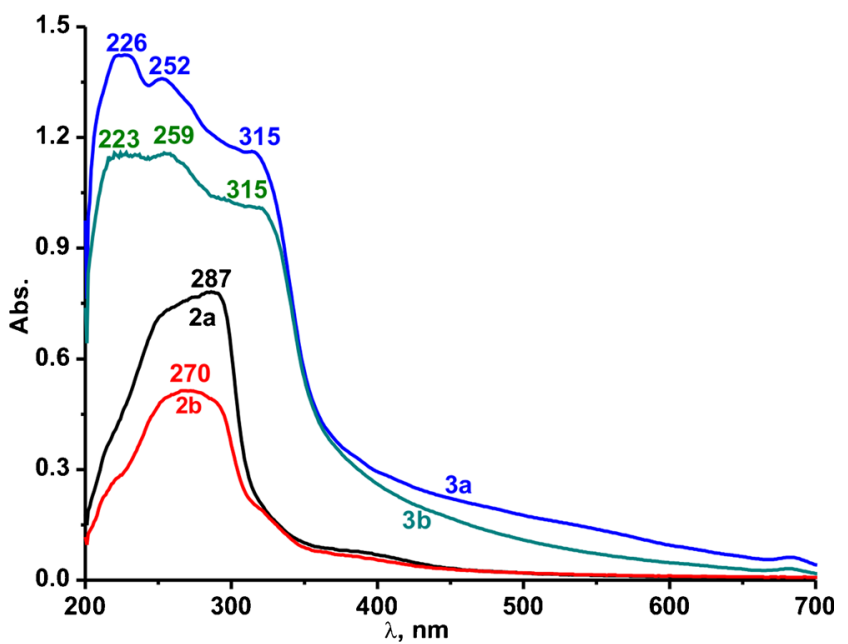

Figure 2. The solid state UV-vis spectra of $\mathbf{2 a}, \mathbf{2 b}, \mathbf{3} \mathbf{a}$ and $3 b$.

In solid state, the strong absorption was observed with bathochromic shift from $\mathbf{2}$ to $\mathbf{3}$. In $\mathbf{2 a}$ and $\mathbf{2 b}$, an absorption band arises at 287 and $270 \mathrm{~nm}$ respectively, while in 3a, the absorption arises at 226, 252 and 315 nm, while 3b shows absorption bands at 223, 259 and $315 \mathrm{~nm}$. The absorption in solid state is red shifted compared to solution spectra due to inter molecular stabilization of the molecules in the solid phase.

\subsection{Single crystal $X$-ray structure of $\mathbf{3 a}$ and $\mathbf{3 b}$}

The solid state structures of $\mathbf{3 a}$ and $\mathbf{3 b}$ were unambiguously determined by single crystal X-ray diffraction techniques. The structural parameters are listed in table 2. The selected bond distance and bond angles are accumulated in table 3. Molecules $\mathbf{3 a}$ and $\mathbf{3 b}$ were crystallized in monoclinic space group, $P 2_{1} / \mathrm{c}$ and $C 2 / \mathrm{c}$ respectively. Molecular structures of $\mathbf{3 a}$ and 3b are isostructural (figures 3-6). Thus, the structural feature of $\mathbf{3 a}$ is discussed in detail. Interestingly the biphenyl rings are on the same plane. The reason for being biphenyl rings on the same plane

Table 2. Crystallographic data, details of data collection and structure refinement parameters for $\mathbf{3 a}$ and $\mathbf{3 b}$.

\begin{tabular}{|c|c|c|}
\hline & $3 \mathbf{a}$ & $\mathbf{3 b}$ \\
\hline Empirical formula & $\mathrm{C}_{18} \mathrm{H}_{20} \mathrm{~N}_{4} \mathrm{SeBr}$ & $\mathrm{C}_{6.5} \mathrm{H}_{6.5} \mathrm{NSe} 0.5$ \\
\hline Formula weight & 500.37 & 552.44 \\
\hline Temperature (K) & 150 & 150 \\
\hline Crystal system & Monoclinic & Monoclinic \\
\hline Space group & $P 2_{1} / c$ & $C 2 / c$ \\
\hline$a, \AA$ & $13.3310(5)$ & $24.2299(17)$ \\
\hline$b, \AA$ & $10.0589(3)$ & $8.6581(5)$ \\
\hline$c, \AA$ & $7.7456(3)$ & $13.6583(7)$ \\
\hline$\alpha,^{\circ}$ & 90 & 90 \\
\hline$\beta, \circ$ & $96.485(3)$ & $119.926(9)$ \\
\hline$\gamma, \circ$ & 90 & 90 \\
\hline Volume, $\AA^{3}$ & $1031.99(6)$ & $2483.3(3)$ \\
\hline$Z$ & 2 & 4 \\
\hline$\rho_{\text {calc }}, \mathrm{mg} \mathrm{mm}^{-3}$ & 1.6101 & 1.4775 \\
\hline$\mu, \mathrm{mm}^{-1}$ & 4.590 & 3.873 \\
\hline$F(000)$ & 497.8 & 1108.0 \\
\hline Data collected & 6.68 to $141.48^{\circ}$ & 7.46 to $141.58^{\circ}$ \\
\hline Unique data & 1859 & 2362 \\
\hline$R_{\text {int }}$ & 0.0151 & 0.0279 \\
\hline GOF on $F^{2}$ & 1.040 & 1.036 \\
\hline$R_{1}$ values (all data) & 0.0300 & 0.0554 \\
\hline w $R_{2}$ values (all data) & 0.0772 & 0.1323 \\
\hline
\end{tabular}

Table 3. Selected bond lengths $[\AA]$ and angles $\left[{ }^{\circ}\right]$ of $\mathbf{3 a}$ and $\mathbf{3 b}$.

\begin{tabular}{lcccccr}
\hline & \multicolumn{3}{c}{ Bond lengths $[\AA]$} & & & \multicolumn{3}{c}{ Bond angles $\left[^{\circ}\right]$} & \\
\cline { 1 - 3 } \cline { 5 - 6 } & $\mathbf{3 a}$ & $\mathbf{3 b}$ & & & $\mathbf{3 a}$ & $\mathbf{3 b}$ \\
\hline $\mathrm{C}-\mathrm{Se}$ & 1.874 & 1.850 & & $\mathrm{~N}-\mathrm{C}(\mathrm{Se})-\mathrm{N}$ & 105.7 & 105.3 \\
$\mathrm{C}(\mathrm{Se})-\mathrm{N}$ & 1.355 & 1.357 & & $\mathrm{~N}-\mathrm{C}-\mathrm{C}(\mathrm{Ph})$ & 112.96 & \\
\hline
\end{tabular}




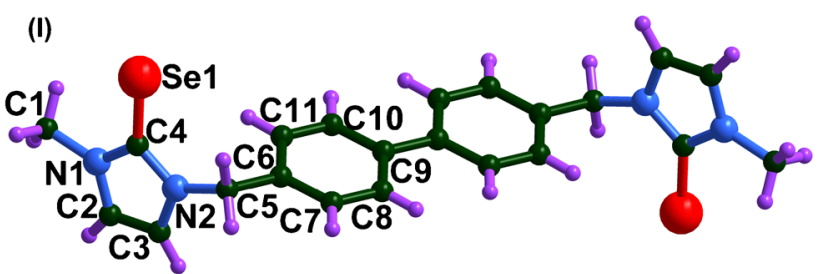

(ii)

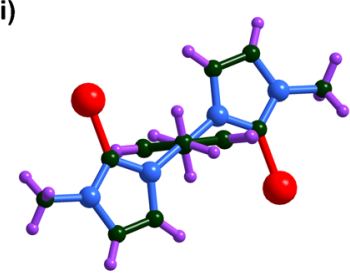

(iv)

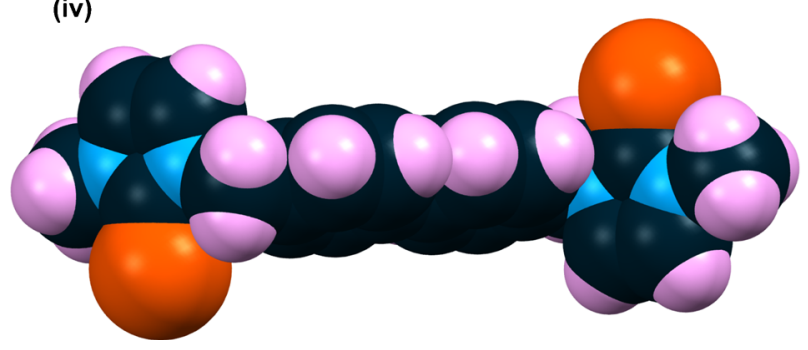

Figure 3. (i) Molecular structure of 3a; (ii) Non-planar orientation of selone with respect to biphenyl planes; (iii) Trans orientation of selone with respect to biphenyl planes; (iv) Space filling model of $\mathbf{3 a}$.

is unclear because the aryl-aryl pi-pi interaction is absent. However, this can be due to the crystal packing effect. The $\left[(\mathrm{HCN})_{2} \mathrm{C}(\mathrm{Se})\right]$ heterocyclic rings are oriented in the trans position with respect to biphenyl plane. The $(\mathrm{Ph}) \mathrm{CC}\left(\mathrm{H}_{2}\right) \mathrm{N}($ Imidazole $)$ angle is close to $112^{\circ}\left(112.96^{\circ}\right.$ for $\mathbf{3 a}$ and $111.86^{\circ}$ for $\left.\mathbf{3 b}\right)$. The $\mathrm{NC}(\mathrm{Se}) \mathrm{N}$ angle observed in $\mathbf{3 a}\left(105.7^{\circ}\right)$ and $\mathbf{3 b}\left(105.3^{\circ}\right)$ are comparable with that of reported selone, $\mathrm{C}_{11} \mathrm{H}_{16} \mathrm{~N}_{4} \mathrm{Se}_{2}$ $\left(105.3^{\circ}\right){ }^{1}$ The $\mathrm{C}=$ Se bond length in 3a $(1.874 \AA)$ and $\mathbf{3 b}(1.850 \AA)$ are also comparable with that of $\left[\mathrm{MeN}(\mathrm{HC})_{2} \mathrm{~N}\left(\mathrm{CH}_{2}\right)_{2} \mathrm{C}(\mathrm{Se})\right]_{2}(1.846 \AA) .{ }^{1}$ Thus, the $\mathrm{C}=\mathrm{Se}$ bond distance can be described as double bond in nature. The $\mathrm{N}-\mathrm{C}(\mathrm{Se})$ bond distance in $\mathbf{3 a}$ are same (1.355 $\AA$ and $1.356 \AA$ ), which are comparable to that of 3b (1.357 $\AA$ and $1.342 \AA)$.

Notably the molecular packing of $\mathbf{3 a}$ and $\mathbf{3 b}$ are nearly comparable. Molecules $\mathbf{3 a}$ and $\mathbf{3 b}$ are arranged in a zigzag one dimensional polymeric structure without any interaction (figures 4 and 5). As shown in figures 4 (right) and $5 \mathrm{~b}$ the similar such one-dimensional polymeric arrangements are packed as close as possible through $a$ axis for $\mathbf{3 a}$ and $b$ axis for $\mathbf{3} \mathbf{b}$.
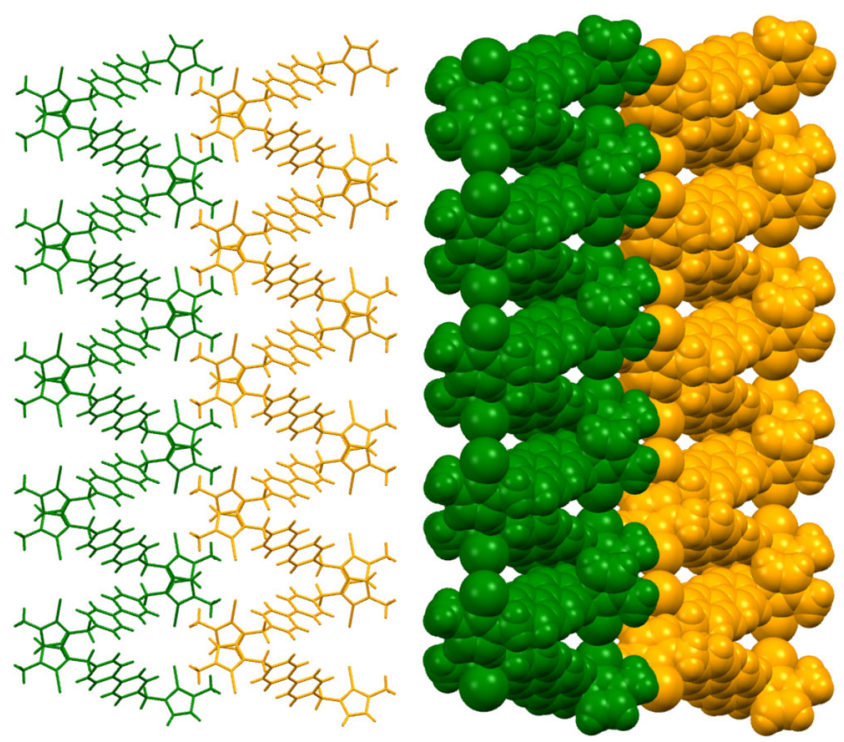

Figure 4. Left: Molecular packing of 3a view along a axis; Right: Space filling model of molecular packing of $\mathbf{3 a}$.

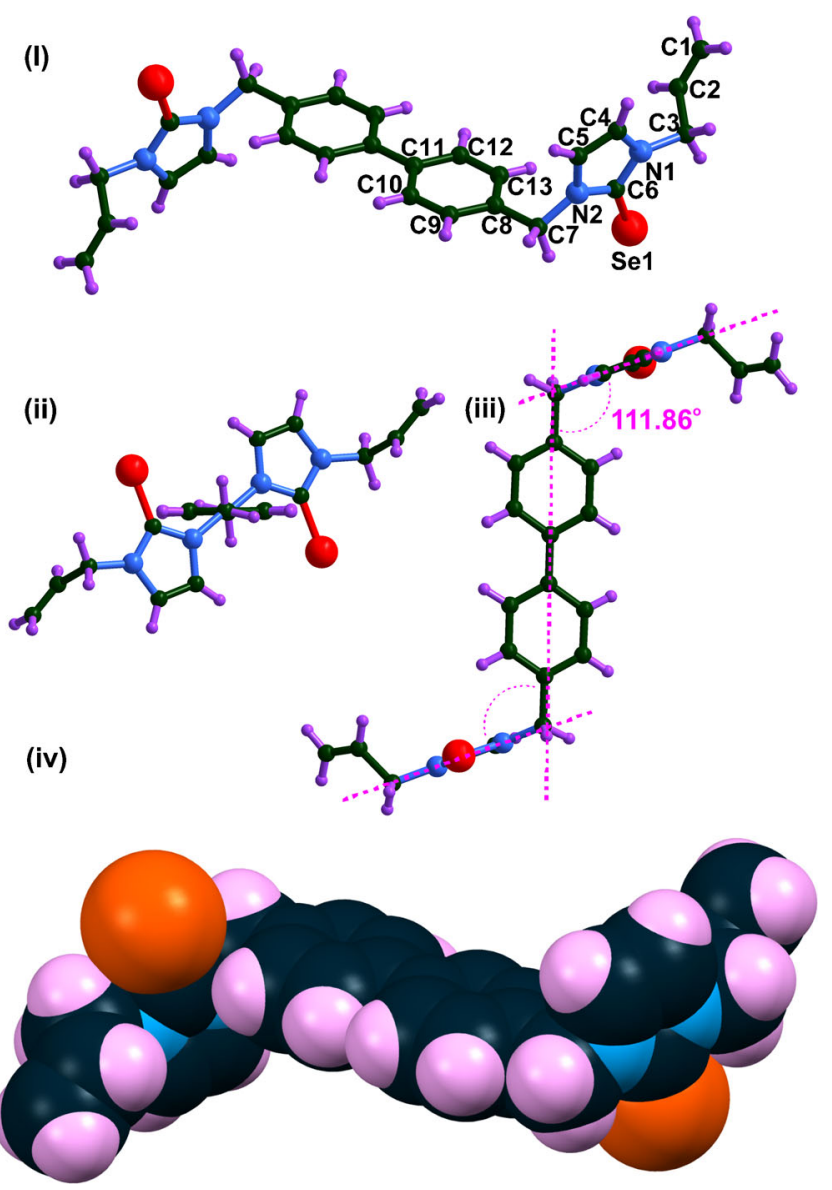

Figure 5. (i) Molecular structure of 3b; (ii) Non-planar orientation of selone with respect to biphenyl plane; (iii) Trans orientation of selone with respect to biphenyl plane; (iv) Space filling model of $\mathbf{3 b}$. 
(a)

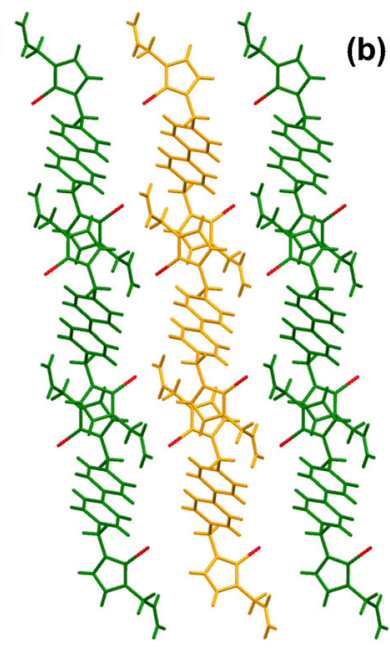

(b)

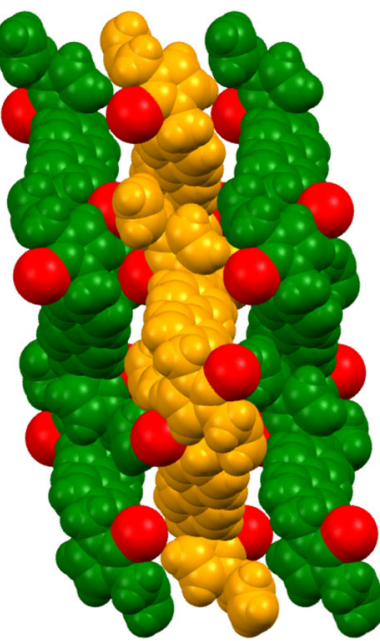

Figure 6. (a) Molecular packing of $\mathbf{3 b}$; view along b axis; (b) Space filling model of molecular packing of $\mathbf{3 b}$.

\section{Conclusions}

In summary, the new allyl and methyl imidazolium salts, $\mathbf{2 a}$ and $\mathbf{2 b}$, and their corresponding diseleniated compounds, 3a and $\mathbf{3 b}$ separated by aromatic spacer were synthesized. The smooth formation of compounds $\mathbf{2 a}, \mathbf{2 b}, \mathbf{3} \mathbf{a}$ and $\mathbf{3 b}$ were proved by multinuclear NMR (1D and 2D), UV-vis (solid and solution state), FTIR and single crystal X-ray diffraction techniques. The long biphenyl spacer in $\mathbf{3 a}$ and $\mathbf{3 b}$ is expected to keep the reactive centres $(\mathrm{C}=$ Se bond mainly) far apart from each other. As reported for monoselone, the diselone compounds are expected to be more efficient in biological activities as more than one $\mathrm{C}=$ Se moieties are there, in which the Se center acts as nucleophile towards some harmful moieties, which are generated in biological systems.

\section{Supplementary Information}

CCDC 994138-994139 contains the supplementary crystallographic data for this paper. These data can be obtained free of charge from the Cambridge Crystallographic Data Centre via www.ccdc.cam.ac. uk/data_request/cif or from the Cambridge Crystallographic Data Centre, 12 Union Road, Cambridge CB2 1EZ, UK; fax: +44 1223336 033; or e-mail: deposit@ccdc.cam.ac.uk.

\section{Acknowledgements}

We gratefully acknowledge the Council of Scientific and Industrial Research (01(2529)/11/EMR-II) for financial support. AS and KS thank UGC for the fellowship.

\section{References}

1. Bhabak K P, Satheeshkumar K, Jayavelu S and Mugesh G 2011 Org. Biomol. Chem. 97343

2. MacMillan-Crow L A, Crow J P, Kerby J D, Beckman J S and Thompson J A 1996 Proc. Natl. Acad. Sci. U. S. A. 9311853

3. (a) Rubbo H, Radi R, Trujillo $M$, Telleri R, Kalyanaraman S B, Kirk M and Freeman B A 1994 J. Biol. Chem. 269 26066; (b) Violi F, Marino R, Milite M T and Loffredo L 1999 Diabetes/Metab. Res. Rev. 15 283

4. (a) van der Vliet A, Eiserich J P, Halliwell B and Cross C E 1997 J. Biol. Chem. 272 7617; (b) Sampson J B, Ye Y, Rosen H and Beckman J S 1998 Arch. Biochem. Biophys. 356 207; (c) Wu W, Chen Y and Hazen L 1999 J. Biol. Chem. 274 25933; (d) Bruck T B, Fielding R J, Symons M R and Harvey P J 2001 Eur. J. Biochem. 268 3214; (e) Monzani E, Roncone R, Galliano M, Koppenol W H and Casella L 2004 Eur. J. Biochem. 271 895

5. Bhabak K P and Mugesh G 2010 Inorganica Chimica Acta $\mathbf{3 6 3} 2812$

6. Roy G, Nethaji M and Mugesh G $2004 \mathrm{~J}$. Am. Chem. Soc. 1262712

7. Guziec L J and Guziec F S Jr. 1994 J. Org. Chem. 59 4691

8. Collins C A, Fry F H, Holme A L, Yiakouvaki A, Al-Qenaei A, Pourzand C and Jacob C 2005 Org. Biomol. Chem. 31541

9. Battin E E and Brumaghim J L 2008 J. Inorg. Biochem. 1082036

10. Battin E E, Zimmerman M T, Ramoutar R R, Quarles C E and Brumaghim J L 2011 Metallomics 3 503

11. Teresa A M, Concepción G M, Kulcsar M, Laguna A and Lippolis V 2011 Eur. J. Inorg. Chem. 2884

12. Jia W G, Huang Y B, Lin Y J and Jin G X 2008 Dalton Trans. 5612

13. Huffer A, Jeffery B, Waller B J and Danopoulos A A 2013 Comptes Rendus Chimie 16557

14. Perrin D D and Armarego W L F 1988 Purification of laboratory chemicals, 3rd Ed. (London: Pergamon Press)

15. Dolomanov O V, Bourhis L J, Gildea R J, Howard J A $\mathrm{K}$ and Puschmann H 2009 J. Appl. Cryst. 42339 